\title{
ROLE OF INFORMATION SCIENCE IN SUSTAINABLE DEVELOPMENT: SIERRA LEONE AS A CASE STUDY
}

\author{
Emerson Abraham, JACKSON \\ University of Birmingham, United Kingdom, e-mail EAJ392@bham.ac.uk / emersonjackson69@gmail.com
}

\begin{abstract}
IS / ICT is dictating the world in terms of service provision, and more so in education and the financial sector such as electronic money transfer. The article has provided a review of Information Science (IS) in the light of its wider interpretation in different walks of life. The current state of IS / ICT provision is also addressed, with the need to focusing attention in improving the country's capacity in meeting global demand for services. Qualitative interpretation of themes was used in helping to provide critical approach in unravelling issues for the good of the nation. Recommendations pointed to an enhancement in the infrastructural capacity, and also human resources to address on-going demands. IS / ICT capacity around the world is changing and so too is the need for the country to build on its human resource potential to address threats posed, from within and outside of the country, while at the same time focusing attention in enhancing the green economy.
\end{abstract}

KEY WORDS: Information Science (IS); Sustainable Development; Information and Communication Technology (ICT); Education; Economic Growth; Sierra Leone

\section{INTRODUCTION}

Information science is taking its toll in all corners of the world; through transition from archaic means of paper filing cabinets to electronic / virtual documentation system. The long term sustainability and economic growth of a country, and more so the globalisation of the world as a whole, rest on the smooth flow of electronic access and data sharing. Despite its downside (which may include threats of hacking), the global economy as it stand cannot sustain itself without electronic / virtual means of data transfer.

The general concept of IS is vastly used to incorporate academic publishing, data modelling, biometrics, document management, human computer interface (HCI), information retrieval, intellectual property, ontology and many more (Bawden, 2001: 219 and Wikipedia, n/d). According to Bawden (ibid), the concept of information science has brought the world closer in the era of computer / information literacy, which throughout the 1980s, and even up to some part of the 1990s had maintained low level in terms of accessibility, while at the same time, the presence of media literacy was making its way in the public domain during the late 1990s (and so too with network and digital literacy in the same period).

Information science (IS), a concept involving the collection, classification, manipulation, storage, retrieval and dissemination of information, has developed its origin as the common stock of human knowledge (Wikipedia Online, n/d). According to Benoit (n/d), "Information science is that discipline that investigate the properties and behaviour of information, the forces governing the flow of information, and the means of processing information for optimum accessibility and usability". Lately, the world-wide-web (www), commonly referred to as the 'Internet' seem to be dominating access to information, and more so in sustaining easy means of data sharing on a global scale (Spink et al, 2001). In every corners around the world, information science (through access to the Internet) is playing great part in ensuring organisations achieve their (corporate) 'objectives', thereby enhancing scope for profit, as in the case with private businesses or realising outcomes from 'value for money' investment as in the case with public or non-governmental organisations. Information science support the use of information / data codes to enable easy means of transmission (both natural and artificial) of information using available devices like computer programming systems (Benoit, 2001; Borko, 1968).

In the $21 \mathrm{st}$ century (dictated by the Information Age), information science is transcending beyond filing cabinet / data archiving, and more so in the direction of accessible virtual information systems thereby making it possible for individuals, institutions and nations to operate at a sustainable level. Big organisations in society, for example central banks around the world and other financial institutions are relying heavily on the use of data to help model / forecast economic outcomes; an easy means of accessing information through electronic method, which makes life much easier for decision making to be determined in relation to the direction of economic progress. In present day, information science is perceived as an ontological process through which knowledge is shared by easy means of virtual / online data transfer within the shortest possible time.

\section{HISTORICAL LITERATURE OF INFORMATION SCIENCE}

Information analysis has been carried out by scholars as early as in the time of the Abyssinian Empire with the emergence of 'cultural depositories' (or libraries as in modern day 
language). Institutionally, IS emerged in the 19th century along with many other social science disciplines. According to Wikipedia online (n/d), the concept finds its institutional roots in the history of science, beginning with publication of the first issue of Philosophical Transactions, generally considered the first. As outlined by Benoit (2001). IS is endeavouring to make its way through all forms of human interaction, incorporating physical form of knowledge; its original form was based on a view of the object (books, computer files and databases).

The concept of information science derived its current meaning from the singular word 'INFORMATION', which according to the primitive era of human communication involved a simple method of tying knots and drawing pictures in all expressive forms; supposedly started around the $3000 \mathrm{BC}$ period, the latter (drawing) then evolved into four different systems of writing: Hieroglyphics by Egyptians, Cuneiform by Mesopotamians, Maya by Central Americans, and Oracle-Bone Scripture by Chinese (Xue-Shan, 2011: 511).

The word 'information' is evolving, taken from the Latin verb informare, meaning to inform, with its noun form (information), introduced into English via the old French language at a later stage in human history (Xue-Shan, ibid). According to Craige (1931), also cited in Xue-Shan (ibid), it is thought that "after the word information was introduced into the English from old French, its original spelling was not information, but at least incorporating six other spelling forms been integrated into English at different times: informatiou, informacioun, informatyoun, informacion, informacyon, and information"; the present day spelling as used in English became more stabilised in the seventh century, and now the dominant of all earlier spellings experimented. According to Shan's (ibid), the word information as used in English Literature is very much akin to concepts such as "news or fact":

"Not mentioning a word of my disgrace, because I had hitherto no regular information of it, and might suppose myself wholly ignorant of any such design (Swift, 1727).

His mouth certainly looked a good deal compressed, and the lower part of his face unusually stern and square, as the laughing girl gave him this information (Brontë; 1847)".

Moving on, the word has become part of every disciplines in life, with the earliest of this introduced in the neuroscience field by the Spanish anatomist, Santiago Ramón Y Cajal in 1888 , and that through "information" two nerve cells could interact with each other ( $\mathrm{Xu}, 2002$ : 86). According to XueShan (2011), the German embryologist in 1908 together with Hans Driesch introduced the term "information" into genetics at the same time with the proposition of the concept of "positional information" (also cited in Driesch, 1929). As expressed by Fisher (1920), the word information denote: "The efficiency of a statistic is the ratio which its intrinsic accuracy bears to that of the most efficient statistic possible; it expresses the proportion of the total available relevant information of which that statistic makes use".

The discipline of information science originated in 1959, at the Moore School of Electronic Engineering, University of Pennsylvania, USA, with focus on computer program, and a minimal attention on the key word surrounding 'information' (Wellisch, 1972). The convening of an international conference on 'computer science' held in 1963 at the Northwestern University then adopted a new name 'Computer and Information Sciences' (Julius and Richard, 1964). According to Xue-Shan, 2011 (also cited in ACM, 1968), 'the idea was noted by the Curriculum Committee on Computer Science of the Association for Computing Machinery in 1968, which then advocated for the discipline of Information Science, or a compromise, 'Computer and Information Science'.

The birth of IBM technology also helped in the progress towards the information science discipline with the computer used as a powerful storage, retrieval and communication channel; this was also backed by Luhn's (1959) observation of a machine "that holds all the words of a document really is holding symbols: all that was lacking was an algorithm that would match these symbols to something people wanted: information" (as cited in Benoit, $\mathrm{n} / \mathrm{d}$ ). This also gave way to the librarianship movement in the discipline of information science with regard to information retrieval and storage in the 1960s, and for which Baldwin (1996) advocated for the adoption of the Library Bill of Rights, with emphasis on "access. (also cited in Benoit, $\mathrm{n} / \mathrm{d})$ ".

\subsection{Information Science in Contemporary Discourse}

As the plunge continues in the quest for an explanation of the concept of information science (also referred to as Information and Communication Technology - ICT), there were also emerging concepts used synonymously, and as expressed by Xue-Shan (2011), these include 'Cybernetics and Information Theory', and then followed by a wide application to the more more commonly used concepts like computer and communications technology; this also gave rise to a gradual shift of concepts around the 1980s in the direction of "information theory" / "informatics" / "information science". The wide contextual usage of the concept of information science was pronounced through the work of an AustrianAmerican knowledge economist, Fritz Machlup in 1982 as explained by Xue-Shan (2011) in one of his eight-volume series titled 'Knowledge: Its Creation, Distribution and Economic Significance', and with discussions revolving around an economics view-point; besides all its associated link with words such as "Computer and Information Science" and "Library and Information Science", he was able to unearth 39 information-related disciplines as outlined below:

Bibliometrics, cybernetics, linguistics, phonetics, psycholinguistics, robotics, scientometrics, semantics, semiotics, systemics; cognitive psychology, lexicology, neurophysiology, psychobiology; brain science, cognitive science, cognitive neuroscience, computer science, computing science, communication science, library science, management science, speech science, systems science; systems analysis; automata theory, communication theory, control theory, decision theory, game theory, general system theory, artificial-intelligence research, genetic-information research, living-systems research, pattern-recognition research, telecommunications research, operation research, documentation, cryptography (Machlup and Mansfield, 1983: $6)$. 


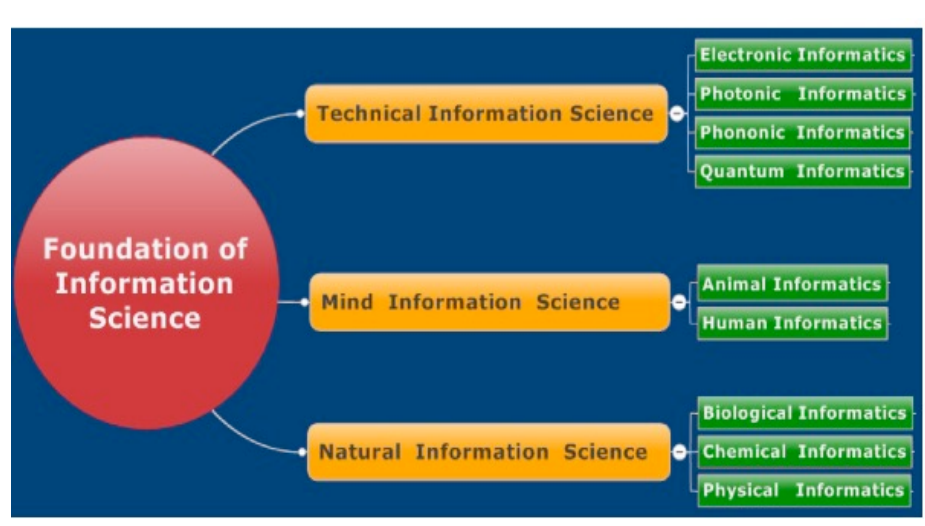

Source: Xue-Shan, 2011

Figure 1. Simple diagram showing contemporary information disciplines system

According to Xue-Shan (2011), the above contemporary information discipline was formulated on the basis of inductive philosophy, thereby giving rise to the following three classes of information science, and followed by seven kinds of informatics:

"This class of information science can form three kinds of information disciplines.

(1) Subbase research: Information material science is available now;

(2) Sign research: Semiotics is available now;

(3) Information research: When we refer to it as a pure information science, Shannon's information theory, genomics, and some parts of human informatics in the future could be included. Pure information science is the most ideal information discipline among all the information studies;

II. Binary information science. This class of information science can form three kinds of information disciplines too:

(4) Subbase research + Sign research: Electronic informatics, photonic informatics, phononic informatics, quantum informatics are available now. These information disciplines are commonly known as technical information science; their basic characteristics are that they need not inquire what information is and what information content should be studied. It is so strange that a so-called information science does not have a corpus inquiry. We believe that we shall understand this more fully someday. An information science is not an information science unless an information corpus is considered;

(5) Subbase research + Information research: Not available definitely, because all information must be nested by sign;

(6) Sign research + Information research: This kind of information science is hard to explain clearly right now. Linguistics seems to part of this exploration, but according to our preceding discussion, linguist Saussure and other philosophers, it is a kind of Semiotics;

III. Ternary information science. This class of information science can only form one kind of information discipline:

(7) Subbase research + Sign research + Information research: The current physical informatics, chemical informatics, biological informatics are the standard paradigms of ternary information science. As to mind information science, it is another complex kind, hard to explain clearly now too. Mind information science has a complicated relationship with psychology, and psychology is a representation theory of neuro-informatics. However, neuro-informatics is a branch of biological informatics according to our systematization. In a sense, psychology is a bridge that connects neuro-informatics to the human informatics".

\section{SUSTAINABLE DEVELOPMENT EXPLAINED AND ITS APPLICATION TO INFORMATION SYSTEMS}

The term sustainable development is a common phenomenon used in modern day society, encompassing developmental approaches in meeting the present needs of society, while at the same time maintaining a balance for the future generation (Jackson and Jackson - Forthcoming). According to the Centre for Environment Education (2007), the concept designed is to "maintain a balance between the human need to improve lifestyle and feeling of well-being on one hand, and the preservation of the natural resources and ecosystems on which present and future generations depends. Under the guidance for UK higher education providers' document, the term 'Sustainable development is development that meets the needs of the present without compromising the ability of future generations to meet their own needs (The Higher Education Academy, 2014)' ${ }^{8}$. The concept historically emerged from a concerted effort by the United Nations in 1992; a reaffirmation of its conference on the Human Environment held in Stockholm, Sweden (5th - 16th June, 1972) to address a new goal and equitable partnership between states, and key sectors of society to protect the global environment and developmental systems (United Nations, 1992).

A successful sustainable development approach, whether instituted by a national government or a cooperative venture between local and international organisations, will always come at a cost, and hence those engaged in it must ensure effective management and transparency is maintained by those on which funds is to be entrusted (for example the UN and World Bank). Information Systems (IS) continue to dominate the world in terms of productivity / output, and economic growth as a result of high quality service delivery; amidst this great development, is human fear in terms of the environmental concerns posed, which includes radioactive emission, noise and sometimes wastage (Watson et al, 2010). Sierra Leone has endeavoured to see herself through the process of engaging in IS/ ICT in a bid to keeping sustainable pace globally; evidence produced from a survey conducted by Statistics Sierra Leone (2013) supports high demand in service usage, particularly so in ICT (for example, telecommunication incorporating mobile phone usage with wifi technology).

Despite the stride towards effective use of information science in the country, its capacity to keep pace with the global economy is very limited (Mangesi, 2007; GOSL / Ministry of Information \& Communication, 2009), more so as a result of weak infrastructure and information-use policy, which so far is considered a deterrent to attracting foreign investments, and the instability in the political environment, a common phenomenon in the sub-region. It is the wish of post-conflict successive governments in Sierra Leone to integrate ICT in the stride to

\footnotetext{
${ }^{8}$ This is also rooted on the three pillar of sustainability (economic, social and environmental factor) emanating from the United Nations World Summit held in 2005, and for which IS / ICT is a contributing factor in modern day society for sustained progress and development
} in society. 
ensure effective collaboration between government departments, the private sector and the internationalisation of effective governance; this is rooted in the country-wide (Political, Social and Economic) objectives for ICT usage, which is strongly supported by The Telecommunications Act 2006 to ensure licensing is effectively issued and regulation with regard to telecommunications usage; this is also in line with the sustainable use agenda (GOSL / Ministry of Information \& Communication, 2009). Information service in the country is managed through the National Telecommunications Commission (NATCOM), and more so competitively to ensure quality in service provision is determined through open and competitive market, with the potential of enhancing scope for sustainable usage by users in all sectors of the economy.

Since the publication of the ICT use document (GOSL / Ministry of Information \& Communication, 2009), the government has made tremendous effort to highlight the following 11 pillars / areas as integral to the sustained socioeconomic growth through information services (ICT):

- Private Sector Business Activity

- Capacity Building and Human Resources in ICT

- Infrastructure

- Health

- Education

- Natural Resources and Environment

- Agriculture and Food Security

- Good Governance

- Gender, Youth and Social Services

- Media and Civil Society

- Tourism

Amidst the above pillars, it is worth noting that the long-term sustainability of information science / ICT hinges greatly on the effective management of systems to cope with potential 'threats', as outlined by the International Telecommunication Union (ITU - 2015) Connect 2020 Agenda Goal 3 target as stated below:

"the first of which is concerned with threats to the integrity and security of ICTs and the Internet, seeking to minimise the negative impact of cyber security risks, including potential harm to vulnerable groups, while the second and third are concerned with negative impacts on the environment, specifically e-waste and greenhouse- gas emissions". In the present state of the economy, it is very unlikely that the government will be able to meet the capacity in sustaining (e-) security threats posed.

\section{JUSTIFICATION AND OBJECTIVES OF THE STUDY}

This article brings to the fore, the importance of IS in the sustainable development of the Sierra Leone economy. Sierra Leone has gone through turbulent time, more so in her stride to gain equilibrium after a decade of civil crisis that ruptured the fabric of the nation. The post-war economy is trying to keep pace with the global economy through the incorporation of modern information systems, mobile / digital telecommunication in maintaining sustained sectoral progress in the country. There is still milestone to cross through, but a critical approach to IS development is surely the way forward.

In this vein, the objectives of this article is to based on the following highlighted points:
1. Assess the impact of Information Science (IS) in the sustainability of the Sierra Leone economy.

2. Evaluate IS scope for integration in the internationalisation of the global economy.

3. Recommend suggestive actions in addressing the way forward on IS usage in the sustainable development of the SL economy.

\section{METHODOLOGY}

\subsection{Study Area}

The study addresses selected areas in the country (Western Area which cover Freetown, the capital city, and Makeni in the Northern region), particularly with regard to IS in the present and future sustainability in keeping pace with the global economy. The country currently has a population of 5.8 million (scattered across the Northern, Southern, Eastern and Western Area / see Figure 2), and with great potential for expansion due to the country's natural resource wealth capacity (Statistics Sierra Leone, 2013).

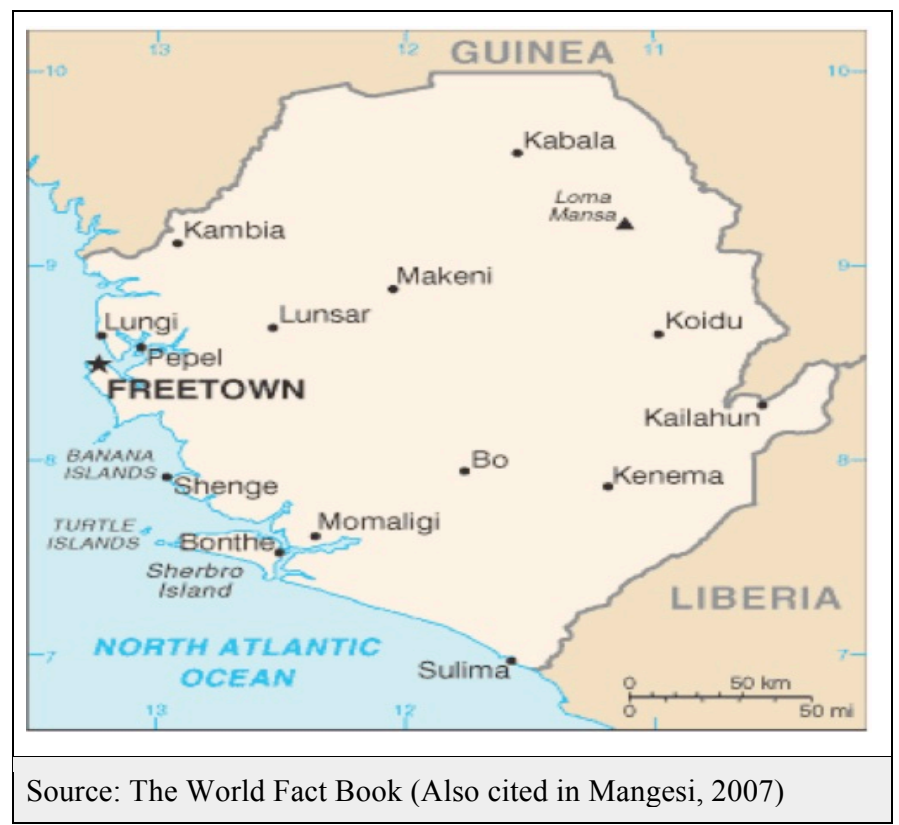

Figure 2. Map of Sierra Leone

During post war era, the country made great stride in sustaining strong economic recovery (4.3\% GDP growth in 2002, $9.3 \%$ in 2003 , and $7.4 \%$ in 2004), propelled by confidence in business, particularly so from foreign investment in the extractive industry and increase in land under cultivation for agricultural production (Mangesi, 2007). The country continued to enjoy steady growth rate up until 2012 as a result of the exploration of Iron-ore deposit around the Northern region, with projected growth rate of $15.2 \%$; these then ended in a gloom with slowdown in global demand for steel production in the latter part of 2012 to the 2013 (Statistics Sierra Leone, 2013).

\subsection{Design of the Study}

The study is based on qualitative investigation (participant observation and interviews) during the researcher's time spent around the country in 2015. Observation was also carried out on how best people (students and staff of IS services) are able to make use of limited facility of IS available at their disposal to execute their daily activities. Investigation (participant) was also carried out through access made around public documentation centres (One public library based around greater Freetown and UNIMAK in the Northern region). 


\subsection{Study Population and Sample}

The population on which this study is based incorporate activities pertaining to the use of IS (data modelling and transfer) by both public and incorporated institutions in promoting effective and sustainable use of technology. In this vein, discussion around such population incorporate three (3) main educational establishments (Fourah Bay College, IPAM and UNIMAK) as a way of supporting the continued progress of teaching and learning in the country. Other public sector institutions (such as the central bank, mandated to carrying out duty of economic management in the country, and two of the main government controlled commercial banks, Sierra Leone Commercial Bank and the Rokel Commercial Bank).

\subsection{Instrumentation, Data Collection Process and Analysis}

The instrumentation is based on qualitative interviews around technology usage in the country (themes and issues shown below in the analysis section) in supporting sustainable growth and development in the economy. In addition, this was also augmented through observation and documentary extraction from public sources like libraries and published articles pertaining to the current state of IS usage in supporting sustainable growth. Given the nature on which data were retrieved, the analysis was focused on the use of NVIVO (with scope for developing categories), and supported by critical discourse analysis of information retrieved from public domain / sources.

\section{ANALYSIS OF THEMES}

Based on the highlighted instruments, the scope for data investigation emerged around the following themes with details of emerging discussions outlined in the next section:

Theme 1: Ease of Access to Educational Resources (at all stages)

Theme 2: Access to information via Public Libraries

Theme 3: Integration / Partnership between Public and Private establishments

Theme 4: International Trade Partnership and Cooperation

\section{Issues Emanating from the above Themes}

- Costs

- Poor network facilitation by providers

- Illiteracy

- Ineffectiveness and poor management of IS / ICT facilities by users / institutions

\section{CRITICAL DISCOURSES BASED ON THEMES}

With reference to the above themes, it is worth noting that discussion is to be addressed critically in order to ensure facilities for IS / ICT integration into the system is robustly addressed. With reference Themes 1 and 2 (ease of educational resources and access to information via public learning resource centre respectively), it is with all intent that information analysed has pointed to the relevance of IS / ICT in making it possible for educational resources to be tapped into by learners regardless of location. The advent of digital learning, for example, virtual learning platforms (for example MOODLE), and also mobile learning gadgets (iPad / Samsung Tablets), as addressed by Jackson (2015; 2016a and 2016b) in three independent studies, has made it possible for learning resources to be easily accessed. Digital learning is not only confined in the classroom context, but with high level of competition faced by both public and private institutions, the use of IS / ICT is highly considered an integral part of the sustained development of an entire economic system. Critical to the sustained reliance of IS / ICT is the need to ensure that systems are sufficiently reliable, and supported by technical expertise to manage their continued existence in meeting the needs of users, both at national and international level. Sierra Leone is still plagued with issues surrounding some of the aforementioned points (for example, poor network provision by providers, and ill-equipped manpower system, also highlighted in Mangesi, 2007). Based on observation from Learning Resource Centre at the selected higher education institutions in the country (for example, UNIMAK and FBC, the then Athens of higher education in the West African region), there are obvious issues which include limited access to ICT facilities available for qualified staff to execute their duties in assisting users to locate vital learning resources. The situation as observed was diabolical, and considered regressive in a $21 \mathrm{st}$ century digital economy, where learning can be easily facilitated through digital means, for example, virtual renewal of loaned items in the confine of a user's environment.

Theme 3, which addresses the importance of IS / ICT in the establishment of partnership between public and private corporations, is very important for the Sierra Leone economy as a way of keeping pace with the global community. It is clear through observation to see that tremendous efforts are being made by the government in incorporating IS / ICT into its strategic operations, and thanks to the international community for their efforts through disbursement of schemes such as financial grants / aid. A bigger part of this is key to the operation of institutions like the central bank which is required to capture essential macroeconomic data to model present and future state of economic performance(s). The independence of IS / ICT systems in (partly) corporate institutions like stated owned commercial banks (for example the Sierra Leone Commercial Bank and Rokel Commercial Bank) is very important in ensuring rapid electronic transfer of data in the digital financial economy. Amidst all the aforementioned point addressed in theme 3, Sierra Leone still have a long way to go in her capacity to keep pace with the international community in terms of public-private partnership relationship in the facilitation of the digital economy. Given the difficulty faced by the country during a decade of civil turmoil, and more so the extortionate cost of recovery, will render the hopes of a sustained IS / ICT economy very remote in the present decade; in order for this to come to reality, strategic objectives will need to be focused in high level of investment in sectors such as education and commerce, and backed by the right level of infrastructural architecture to cope with on-going developments in global technology. The low rate of human capital / development, (which according to Mangesi, 2007 was 35.1\% for people aged 15 and above), will need to be reviewed, and backed by robust learning goals set in place to address the way forward in enabling the adaptability of a sustainable information system in detecting, and dealing with changes taking place within the system and the international environment (Maruster, et al, 2008). This will ensure that system set in place is able to take cognisance of the dynamic environment of global IS / ICT, and with relevant cost-benefit analysis factored in order to ensure that the system is sustainably well managed.

Theme 4 - this was incorporated as part of the need to ensure international partnership with bodies such as ITU is 27 
established, so as to make it possible for the country to review its performance on IS / ICT provision at an approved international benchmark / standard. The annual report of the ITU provide robust review of progress in IS / ICT, and this include issues pertaining to the long term sustainability system(s), in combating threats faced by the system, and finally, issues on the well-being of IS / ICT users through exposure to radioactive emissions and concept around the preservation of the green economy. In the case with Sierra Leone, issues such as low educational attainment, and low capital investment in maintaining systems are some of the problems faced - as already addressed in other themes, the situation can be reduced through robust quality assurance and monitoring of system.

\section{CONCLUSION AND RECOMMENDATIONS}

IS / ICT is the way forward in the current Information Age, both in terms of supporting national economies and corporate establishments move their systems at a sustainable level to address the marketisation of IS service(s) in the global economy. Sierra Leone, amidst all its complexity of problems (a ten year battle of political turmoil, and lately slow-down in growth rate on account of a stagnated global economy around the latter part of 2012), is continuing to make progress in keeping pace with the global need for IS / ICT services through investment in IS infrastructure, and more so supported by the open and competitive marketisation of local business operating under the guidance of NATCOM. The country still have a long way in catching up with trends and development in technology to support its infrastructure, and the sustainability of service provision, for example, low cost IS / ICT services provided to educational establishments in promoting competitive teaching / learning, and also intensive research and development.

Proposed recommendations for this will need to take cognisance of the current infrastructure of IS / ICT in the country as a whole, and the way forward in addressing areas of concerns, for example, a review of IS / ICT curriculum / provision at all levels in the educational system. Review of current provision and capacity will also be needed in the light of future demands for services, but most importantly ensuring the right level of financial investment is championed for a sustained green economy, both in the present and future. As outlined by Kargbo (2005), the country is still faced with emerging challenges with regard to a comparatively low level of financial investment in keeping pace with advancement in technology; making it very difficult for areas such as the education sector to feature well in sustaining global competitiveness in the marketisation of essential services like education and commerce. Unless a proper review of provision for IS / ICT investment is done (in line with the country's needs), there is no way in which the country (more so, public and private / corporate institutions) will be able to surface competitively in the current information age where virtual services is perceived to be the dictate of every walks of life.

\section{ACKNOWLEDGEMENTS}

My sincere appreciation goes to my children (Sona, Hannah and Emerson jnr.) in the process of writing this article; you are my inspiration, and the reason for the effort and time I have dedicated in getting this work completed.

\section{REFERENCE}

1. ACM Curriculum Committee on Computer Science. (1968). Curriculum 68: Recommendations for academic programs in computer science. Commun. ACM, Vol. 11, 151-197.

2. Baldwin, G. B. (1996). The Library Bill of Rights. Library Trends, 45(1), 7-27.

3. Bawden, D. (01 Mar 2001). Information and digital literacies: A review of concepts. Journal of Documentation, $\quad 57(2), \quad 218-259$. DOI: 10.1108/EUM0000000007083.

4. Benoit, G. (n/d). What is information science? Available at: $\quad<$ http://web.simmons.edu/ benoit/rc/WhatIsISdraft1.pdf $>$. (Accessed: 30th November 2015.

5. Borko, H. (1968, Jan.) Information science: what is it? American Documentation, pp. 3-5.

6. Bronte, C. and Eyre, E. (1980). Oxford University Press: London, UK.

7. Centre for Environment Education. (2007). Sustainable Development: An Introduction (Volume 1). Available: $<$ http://www.sayen.org/volume-i.pdfs. (Accessed: 30th November 2015).

8. Craige, W.A. (1931). A Dictionary of the Older Scottish Tongue from the Twelfth Century to the End of the Seventeenth; University of Chicago Press: Chicago, IL, USA.

9. David Bawden, (2001), "Information and digital literacies: a review of concepts", Journal of Documentation, Vol. $57(2), 218-259$.

10. Driesch, H. (1929). The Science and Philosophy of the Organism; I. Gilford Lectures, 1907; II. Gilford. Lectures, 1908. A. \& C. Black Ltd.: London, UK.

11. Fisher, R.A. (1920). Accuracy of observation, a mathematical examination of the methods of determining, by the mean error and by the mean square error. Mon. Not. R. Astron. Soc. Vol. 80, 758-770.

12. GOSL / Ministry of Information \& Communication. (2009). NATIONAL ICT POLICY OF SIERRA LEONE. Available at: $<$ http://mofed.gov.sl/PUBLICATIONS/NationalICTPolicy .pdf $>$. (Accessed: 5 th December 2015).

13. International Telecommunication Union. (2015). Measuring the Information Society Report 2015. Available at:

$<$ http://www.itu.int/en/ITUD/Statistics/Documents/publications/misr2015/MISR2015w5.pdf\#page 79>. (Accessed: 5th December 2015).

14. Jackson, E.A., and Jackson, H.F. (Forthcoming). A Review of Corporate Social Responsibility in Sierra Leone: The impact of Corporate Presence on the Livelihood Sustainability of Natural Resource Communities.

15. Jackson, E. A. (2015). Impact of MOODLE platform on the pedagogy of students and staff: Cross-curricular comparison. Education and Information Technologies, 117. DOI 10.1007/s10639-015-9438-9.

16. Jackson, E.A. (2016a). M-Learning Devices and their impact on Postgraduate Researchers Scope for improved Integration in the Research Community. TOJNED, 104113.

17. Jackson, E.A. (2016b). Proposal for Virtual ICT use in Sierra Leone Education System: A Case of MOODLE. Journal of Applied Thought, Vol. 5(1), 1-17.

18. Julius, T.T.; Richard, H.W. (1964). Computer and Information Sciences: Collected Papers on Learning, Adaptation and Control in Information Systems of Computer and Information Science Symposium, 1963, Northwestern University; Spartan Books: Washington, DC, USA. 
19. Kargbo, J.A. (2005). Managing indigenous knowledge: What role for public librarians in Sierra Leone?, International Information \& Library Review, 37:3, 199207, DOI: 10.1080/10572317.2005.10762681.

20. Luhn, H. P. (1959). IBM report. Technical Report RC-127. Yorktown Heights, NY: IBM.

21. Machlup, F. and Mansfield, U. (1983). The Study of Information: Interdisciplinary Message; John Wiley \& Sons: New York, NY, USA.

22. Mangesi, K. (2007). ICT in Education in Sierra Leone. Available at: <https://www.infodev.org/infodevfiles/resource/InfodevDocuments_427.pdf $>$. (Accessed: 5th December, 2015).

23. Maruster, L; Faber, N.R. and Peters, P. (2008). Sustainable Information Systems: a knowledge perspective. University of Groningen, Faculty of Economics and Business, The Netherlands.

24. Spink, A., Wolfram, D., Jansen, B.J. and Saracevik, T. (2001). Searching the web: the public and their queries. Journal of the American Society for Information Science 53(2): pp. 226-234.

25. Statistics Sierra Leone (2013). 2012 Annual Economic Survey - Economic Statistics Division. Statistics Sierra Leone.

26. Swift, J. (1977). Gulliver's Travels; Pan Books: London, UK.

27. The Higher Education Academy (2014). Education for sustainable development: Guidance for UK higher education providers (June, 2014). Available at:
$<$ http://www.qaa.ac.uk/en/Publications/Documents/Educat ion-sustainable-development-Guidance-June-14.pdf $>$. (Acessed: 6th December 2015).

28. The World Factbook 2007. https://cia.gov/cia//publications/factbook/geos/sl.html. (Accessed: 1st December 2015).

29. United Nations (1992). Rio Declaration on Environment and Development 1992. Available at: $<$ http://www.jus.uio.no/lm/environmental.development.rio .declaration.1992/portrait.a4.pdf $>$. Accessed: 30th November 2015.

30. United Nations World Summit (2005) 2005 World Summit Outcome. Available at: $<$ www.un.org/en/ga/search/view_doc.asp?symbol=A/RES/ 60/1>. (Accessed: 5th December 2015).

31. Watson, R.T., Boudreau, M., and Chen, A.J. (2010). Information systems and environmentally sustainable development: energy informatics and new directions for the community. MIS Quarterly Vol. 34(1): pp. 23-38.

32. Wellisch, H. (1972). From information science to informatics. J. Libr., Vol. 4: 164.

33. Wikipedia Online (n/d). Information Science. Available at: $<$ https://en.m.wikipedia.org/wiki/Information_science\#His tory $>$. (Accessed: 28th November 2015).

34. Xu, K. (2002). An Outline to Neurobiology (In Chinese); Science Press: Beijing, China.

35. Xue-Shan, Y. (2011). 'Information Science: Its Past, Present and Future'. Information 2011, Vol. 2, pp. 510527; doi:10.3390/info2030510. 